\title{
Method for Monitoring and Increasing the Quality of Experience in Cellular Networks Based on Interconnections Between Key Quality Indicators Using Spline-Approximation
}

Jamil Al Azzeh ( $\square$ azzehjamil@gmail.com )

Al-Balqa Applied University https://orcid.org/0000-0002-3525-5471

Roman Odarchenko

BundlesLab

Anastasiia Abakumova

National Aviation University

Serhii Bondar

National Academy Of sciences

Research

Keywords: 5G, mobile network, QoE, QoS, estimation, spline-approximation, monitoring, cellular network

Posted Date: November 12th, 2020

DOI: https://doi.org/10.21203/rs.3.rs-104010/v1

License: (c) (i) This work is licensed under a Creative Commons Attribution 4.0 International License.

Read Full License 
METHOD FOR MONITORING AND INCREASING THE QUALITY OF

EXPERIENCE IN CELLULAR NETWORKS BASED ON INTERCONNECTIONS

\section{BETWEEN KEY QUALITY INDICATORS USING SPLINE-APPROXIMATION}

Jamil Al-Azzeh ${ }^{1}$, Roman Odarchenko², $\square$ Anastasiia Abakumova ${ }^{3}$, Serhii Bondar $^{4}$

1-Computer Engineering Department, Faculty of Engineering Technology, Al-Balqa Applied University, Amman, Jordan

Jamil.azzeh@bau.edu.jo

2-BundlesLab Kft, Budapest, Hungary

roman@bundleslab.com

3 Telecommunication systems department National aviation university Kyiv, Ukraine

abakumova.anast@yandex.com

4-International Research and Training Center for Information Technologies and Systems of the National Academy of Sciences (NAS) of Ukraine and Ministry of Education and Science (MES) of Ukraine

bondar.sehii@yandex.ru 
Abstract. Sustainable and balanced development of the communications industry is inextricably linked with increasing numbers of subscribers and services provided. The current level of development of the cellular services market, qualitative changes in the means and methods of providing services, and the increased volume and diversity of information circulating in cellular networks have evoked the need for service quality assessment system improvement. To maintain competitiveness, the main efforts of operators are aimed at improving quality and increasing the service life of subscribers in the network by ensuring the required level of customer satisfaction in high quality services through a system of organizational-technical and socio-economic measures to bring the achieved level of quality of service (QoS) provision in accordance with the existing, emerging, or projected needs of subscribers. These circumstances determine the relevance of the studied tasks related to the assessment and management of the quality of cellular services and the development of approaches to their solution.

To achieve improved QoS provision, a functional relationship between network parameters has been established, i.e., the impact of key performance indicators on a key quality indicator through the use of cubic Hermitian splines (CHS) has been determined. The use of splines, as a signal model, can significantly improve the quality of signal processing due to the continuity of values and partial derivatives in the joints of spline gluing. CHS are characterized by calculation simplicity, as they provide high speed computing, which, in turn, is important for real time work when processing large data sets. Experimentally, it was shown that the use of splines allows for the ability to calculate statistical estimates of the required parameters of spline approximations, but also their confidence intervals, which increases the accuracy and probability of further calculations and is a distinct advantage of this approach 
The methods of service quality management through machine learning have been improved, which are effective tools for modeling integrated indicators of communication services quality control, monitoring their condition in terms of final copies of services, determining the causes of degradation, and reporting. It monitors the service performance provided by the cellular operator. In addition, the method checks the readiness and availability of services, detects network nodes through which quality degradation occurs, collects various quality metrics, and compares them with pre-installed quality indicators.

Keywords: 5G, mobile network, QoE, QoS, estimation, spline-approximation, monitoring, cellular network.

\section{1-Introduction}

Permanent and balanced development of the communications domain is inseparably connected with increasing subscriber volume and provided services. On the one hand, there is user interest for new service receiving, while on the other hand, competition forces providers to permanently bring in new suggestions for the connection market.

Cellular connection service market modern development level, qualitative changes of devices and service supply method, and increasing the information volume and multidimensionality that circulates in the cellular networks have been put forward for service quality evaluation system modernization problems that define implementation levels of competitive advantages by cellular connection providers.

In the name of competition preservation, providers are increasing the quality and size of network user servicing duration with the development of special loyalty programs and the creation of effective promotion systems of existing and brand new additional cellular connection services. 
The high quality service required for high user satisfaction levels is complex and searches for a system of organizationally-technical and socially-economical events in the name of achieved service quality level reduction with respect to current, inceptive, or forecasted user requirements. Exposed circumstances defined the actuality of problem development connected to the evaluation and control of cellular connection quality.

4G system key productiveness indicators (KPIs) [1, 2] connected to network productivity are derived from previous KPI-systems, where network productivity was considered a key factor in network measurements. Cellular network providers define several limit values for each KPI, below which a network would be considered ineffective. With increased income, providers are constantly oriented to QoE end-users, but problems remain because of the user culture and requirements changing it as a driving force of cellular broadband connection and IP transformation.

User demands and network quality expectations are constantly increasing, which creates a brand new definition of network quality. In some cases, despite the fact that network KPIs point to good network productivity, many providers are still dealing with user complaints about background noise during voice calls and slow webpage loading.

QoE foresees complex psychological and physiological factors [3]. When the question is about service provider or about some concrete network productivity, QoE belongs to end-user satisfaction (Fig. 1) [4]. 


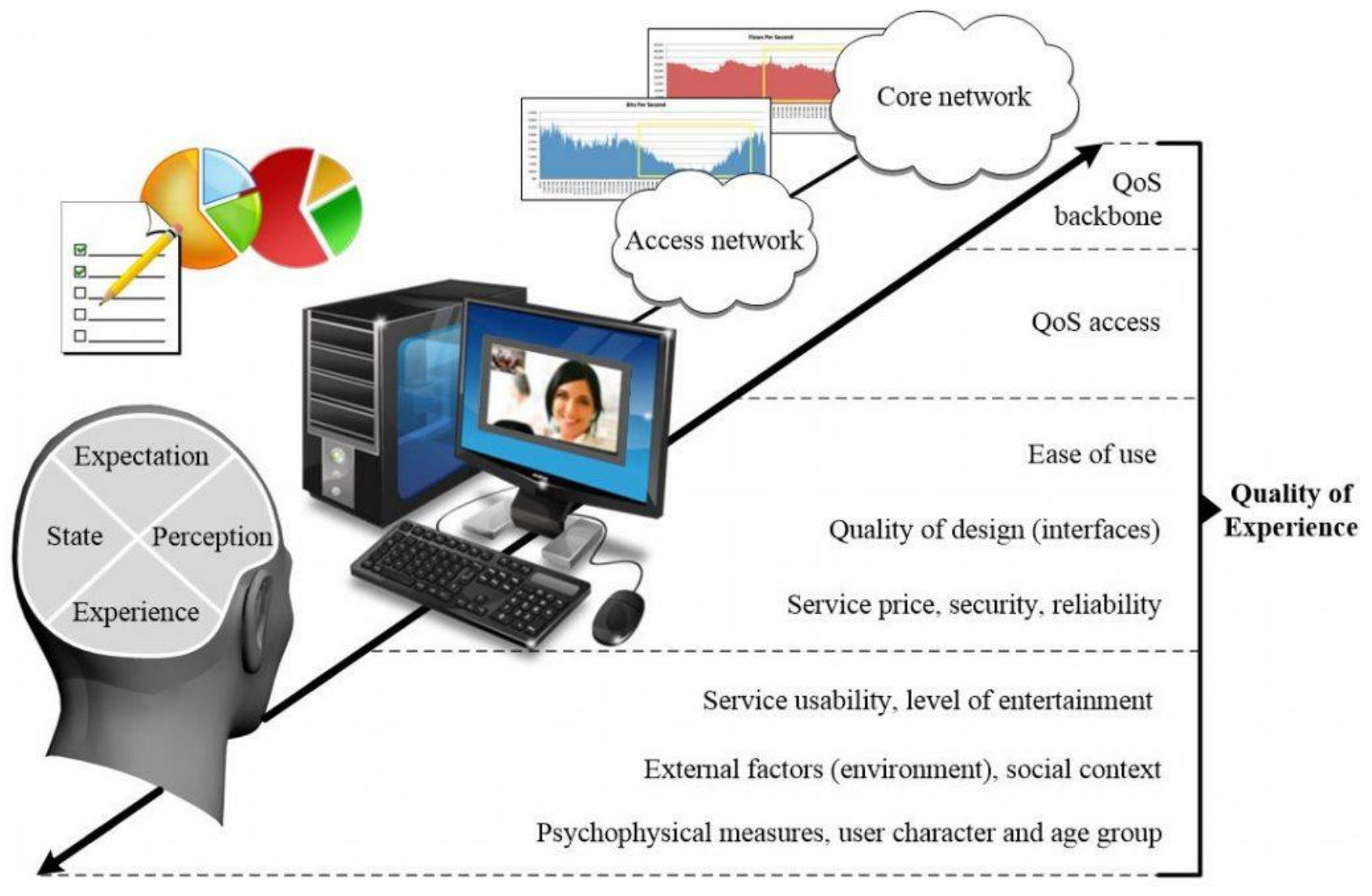

Figure 1. QoE estimation framework [4]

Factors influencing QoE can be divided into technical and nontechnical [5]. Technical are factors connected to terminals and networks, and nontechnical are factors that are connected to politics and services provided by cellular operators. It is difficult to quantitatively define QoE-value through network monitoring and there is a not unified criterion for QoE measurement at the domain [6].

For the evaluation of the values received by service quality monitoring results, statistical data must be calculated with reference to measurements on real traffic [7]:

1) for output requests in representative summation of basic stations to representative summation of destinations;

2) test calls in the representative population of base stations or publicly used separate networks of portable (cellular) connections to the representative population; 
3) combinations of the abovementioned variants.

Usage of test calls or linkings for data transfer is often quite expensive. Observations based on signal information are cheap but are unreliable.

Measurements on real traffic and inner service quality automatic control are accomplished with the help of special technical instruments that do not allow staff interference to support rate and service quality parameters control.

By utilizing the test (control) calls, availability rates, for example "time of the call ending," are being evaluated. Control calls accomplished on the answering machine are connected to the international telephone network, or the public uses networks of portable (cellular) connections for the monitoring procedure [8].

An external method could be statistical data exchange with the administrations of other providers of international and national networks.

Each method has its advantages and disadvantages. With the exception of service quality being received by multiple methods, the following sources are also being used:

$\square$ user complaints;

information from other cellular connection providers;

domain statistical reports of cellular connection providers;

reports of connection providers accomplishing traffic transit through the network of another provider interested in high quality service for their users;

$\square$ data regarding traffic volume measurement.

Statistical methods for designated information processing are used in [9]. With a limited quantity of observations, given methods can generally adopt valid solutions regarding service quality. For clarity, during statistical data processing, tabular and graph-analytical methods for received materials representation are being used. For example, for the readiness rates calculation statistical telecommunication technical device demurrage data, 
telecommunication networks and systems unpreparedness data are being used. During processing, a timeframe is chosen for statistical data processing. Herewith, statistics are based on the results of week and month timeframe measurements, neglecting detailed data and statistical method usage.

Mobile network operators (MNOs) are also using smaller or larger data gathering periods. Quarter term data that is able to provide adequate information is optimal for the majority of service quality parameters [10].

Statistical data analysis methods are also used in calculating several values and availability parameters (percentage of faults, effective call, or connection attempts etc.), quality of voice information transferring, and other rates characterizing quality of provided services.

An additional type of user preference examination is a reference analysis about the low-quality service. User reports have been documented, and MNO has procedures for received data processing. User report analysis is used for service quality rate and user service quality definition.

MNO are obliged [11] to collect the statistics of service quality rates for the aim of internal control (audit) within the limits of current enterprise quality control system.

However, effectiveness rate monitoring is not enough for service quality amelioration. Providers are often having problems with identification or problems that occur with wireless networks, nucleus, or service network. The basic goal of the work is taking place in instrument development that would control and evaluate network status by active testing and passive monitoring. When service quality deteriorates, instruments are needed to analyze the problem from the service layer to the bottom layer, finding the primary cause of service degradation in such a way. 


\section{Related work}

However, in [9] the whole evaluation process has been presented, and it does not include the influence of different user factors for QoE. The forecast model in [9] was optimized in the development $[12,13]$, considering user viewing time, pause time, and other factors $[14,15]$. However, there is no concrete formula, it was just proved that taking into account user behavior factors can increase the QoE forecasting model accuracy. The hypothesis about the existence of training connection between the application network traffic behavior and each respective QoE marker represented in [16] is a new approach. This approach works in the following way: first, the control system data is gathered, where the provider has some service traffic, as the QoE metrics of service. Next, the machine training algorithm is used to learn the dependency function between these rates [17]. The given method fits as the provider for quality support, as the infiniteness of network service providers allows them to analyze different anomalies at furnished services. Furthermore, it could help in diagnosing poor quality using the significant network functions definition. Nonetheless, these methods have limits because of the uncertainty of given data, bad modeling of the behavior of users at needed service and different training methods have different influences on the analysis quality. More complicated training methods can further increase QoE model certainty.

On the basis of the Q-learning algorithm in [18], a HAS client configured to the network status has been proposed. Considering the speed demands for video, network capacity, and repeated buffering, an equation for MOS [19] receiving in [16] has been proposed.

\section{Methods}

The purpose of this paper is is monitoring and increasing of the service extension quality of cellular connection providers based on interconnections installed between the key quality rates using spline-approximation. 
To achieve these goals, the following interconnected problems must be solved in this paper:

1. To analyze modern cellular connection systems for the aim of structural system definition, that are in charge of service providing quality control and pointing of its disadvantages.

2. To define basic key effectiveness rates of the cellular network that have significant influence on service, providing quality to the users by cellular connection providers.

3. Method development of dependency between cellular network parameters for service providing quality evaluation.

4. To develop experimental research of the novel method.

To achieve the goals of the functional relationship between network parameters has been established through the use of cubic Hermitian splines (CHS). Experimental research has proven that the use of splines allows calculate statistical estimates of the required parameters of spline approximations. Also, the method of service quality management through machine learning have been improved.

Thus, to achieve mentioned above goals, the remainder of this paper is organized as follows: Section "Method of service quality control" describes the developed method of service quality control. The model for establishment of functional dependencies between network parameters is described in Subsection "Definition of functional dependency between network parameters based on the spline utilization". Section "Experimental research" reports the experimental results and discussions. Finally, Section "Results and Discussion" describes the experimental dependencies and approximation of different parameters. Finally, Section "Conclusions" summarizes the contributions of the paper and obtained results.

\section{Method of service quality control}


The previous year's tendency, associated with the increasing telecommunication services market, has significantly changed the cellular providers' strategy. For the protection of market share, providers are forced to not only modernize technically provided cellular services that are being provided to the user, but also understand their support services with such challenges as [20]:

- user loyalty increasing;

- new user attraction;

- fast solutions of emerging problems;

- monitoring of service quality in online mode;

- decreasing demurrage time during failures.

The service quality control method, based on machine training, is an effective instrument for integral connection service quality control indicator modeling, monitoring of its status in the context of service-end specimen, searching for degradation reasons, and reporting the organization. It looks after the supplier by the provider service working capacity. Furthermore, this method determines service readiness and availability and locates the network nodes through which quality degradation takes place.

During method development, the following basic goals are being set:

1) Quick use starting: availability of a typical template set of quality values and reports.

2) Flexible solution: quick creation of new service types and quality rates, thus adaptation to the cellular connection provider individual demands.

3) Integration with any OSS/BSS provider system.

4) Each SLA-type control.

Service quality control method graphic representation is shown on Fig. 2. 


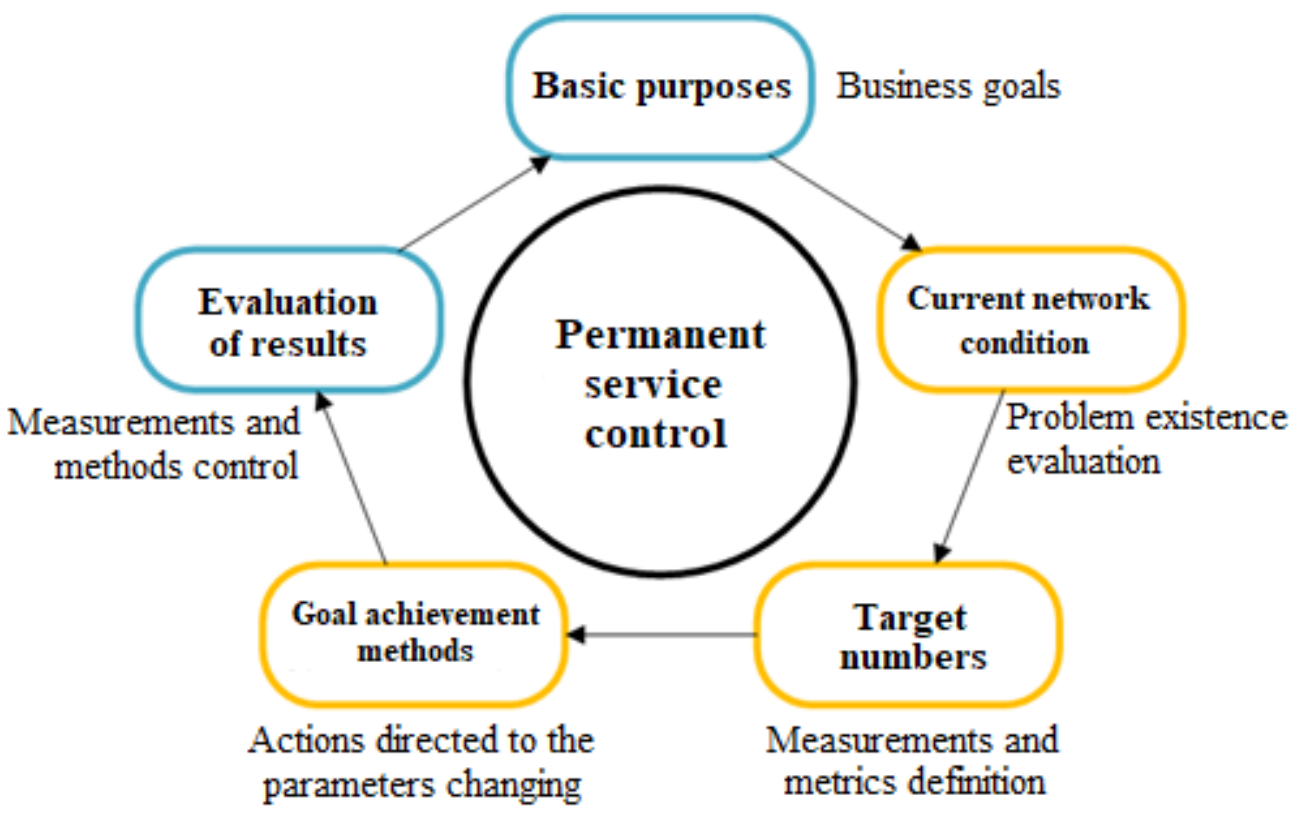

Figure 2. Graphic representation of the service quality control method

A significant place in the control process is taken by user satisfaction characteristics definition process, or QoE. Herewith, each network service provider strives to objectify the QoE parameter evaluation. So, the designed method has been proposed to be used at the given development (Fig. 3). 


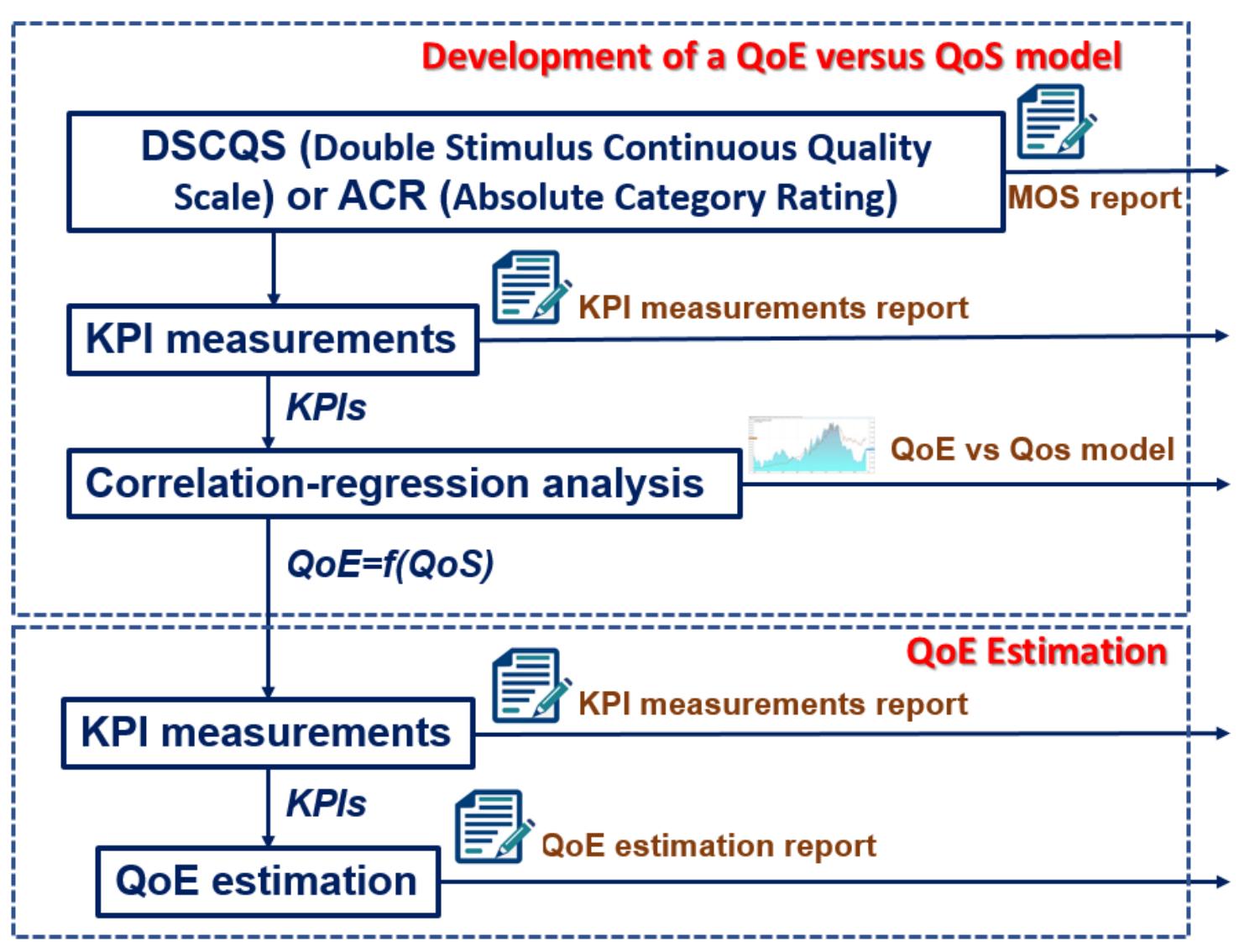

Figure 3. Estimation method of QoE based on KPI measurements

2.1 Definition of functional dependency between network parameters based on the spline utilization

To provide quality by increasing the use of the developed method (Fig. 3,) the functional dependence between network parameters must be defined, or the influence of KPI on key quality indicator (KQI) must be defined [21].

The challenge of functional dependency installation between parameters KPI and KQI could be solved using spline utilization. Using splines, condition [22] must be strictly utilized, which provides steadiness and differentiality (natural smoothness) into merging point (Fig. 4). 


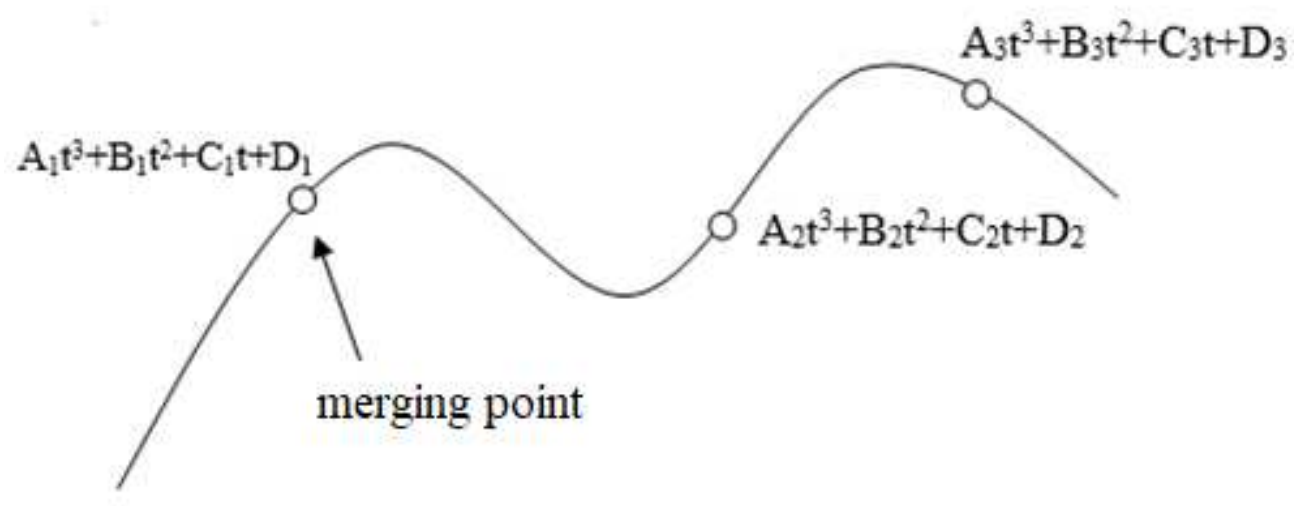

Figure 4. Polynomial spline

It must be mentioned that a basic advantage of splines is calculation simplicity and analysis. Simultaneously, this class of mathematical instrument is considered the best of the linear instruments of approximation.

Over the last years, much research has been focused on developing and analyzing the variety of splines used for a large spectra of applicable goals [23, 24]. However, there is a problem in the understanding of such a form of spline construction that provides effective work during programming.

At the same time, numerous developments of many authors indicate smoothing features of splines that provide minimal values of root-mean-square failures $[25,26]$. Nevertheless, such splines cannot provide guarantees for formal, theoretically proven speedwork during the processing of large data arrays.

Considering [27] spline advantages, it would make sense to use them for defined problem solving.

There are many different ways of spline construction on the basis of their species [28], and the most are local cubic Hermith splines (CHS) [29]. It differs from global versions by the calculation simplicity and effect that it guarantees high speed work during calculations that, in return, are significant for the work in real time during large data array processing. 
For the construction of CHS, merging nodes are located in such a way that spline on the whole interval satisfies conditions of a least squares method (LSM):

$$
\sum_{i=1}^{N}\left[S p_{i}-y_{i}\right]^{2}=\min
$$

where $N$-quantity of counts on the observing interval;

$i-$ count sequential number;

$S p_{i}$-spline;

$y_{i}-$ input data.

After defining formula (1), it can be shown that the summarized square excursion from the function approximated by $y_{i}$ is minimal.

By the next step, planning matrix $\mathrm{P}$ that has block-diagonal structure later on the local function features can be calculated (Fig. 5).

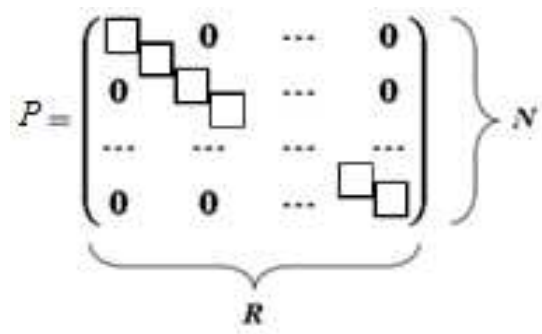

Figure 5. Schematic planning matrix

where squares are square Hermith polynomials;

$R$-quantity of spline merging nodes on the observing interval.

For this, the grid of nodes $\Delta_{\mathrm{R}}$ was found, onto which a spline was constructed. It must be noticed that observing grid $\Delta_{\mathrm{N}}$ and grid of nodes are not necessarily equal, or, in other words, on each grid section, several observations can be located defining the dependency behavior.

Each row for CHS consists of four basic functions, where an approximate view is represented in Fig. 6. Each has a form of cubic polynomials sewed together by the conditions of polynomial steadiness and steadiness of the polynomial first derivative in merging node. 


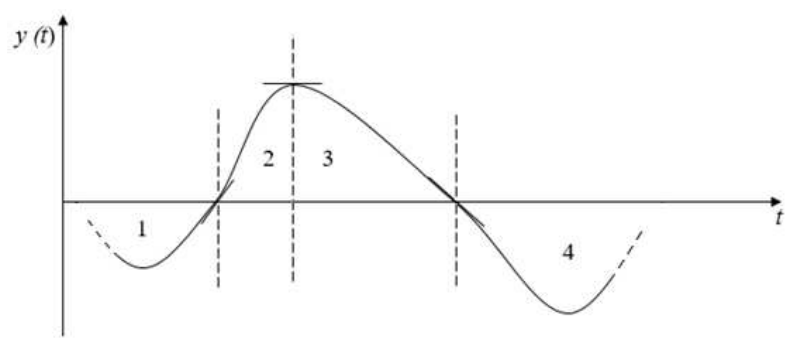

Figure 6. Representation of basic functions

Let us rewrite expression (1) in matrix view:

$$
[S p-Y]^{2}=\min
$$

where $Y$-input data vector.

$$
Y=\left[\begin{array}{c}
y_{1} \\
y_{2} \\
\vdots \\
y_{N}
\end{array}\right]
$$

where $y_{1}-y_{N}-$ input data values.

Let us describe $S p$ spline in the following way:

$$
S p=P * A
$$

where $P$-planning matrix;

$A$-an ordinate vector of spline node merging.

For the construction of the whole CHS, the $A$-spline ordinate vector of the merging nodes must be calculated and it has the form of:

$$
A=\left[\begin{array}{c}
a_{1} \\
a_{2} \\
\vdots \\
a_{R}
\end{array}\right] .
$$

where $a_{1}-a_{R}-$ rates of the spline merging nodes ordinates.

The node ordinate evaluation can be found by the method of least squares, where their optimal rates are constructed relative to maximum verisimilitude.

Sought parameters can be found by way of matrix equation system solving. Considering the (3) expression, the $A$ vector can be found: 


$$
A=\left(P^{T} * P\right)^{-1} * P^{T} * Y
$$

Let us introduce the following markers. Let us assume that:

$$
\begin{aligned}
& C=P^{T} * P, \\
& B=P^{T} * Y
\end{aligned}
$$

Considering expressions (5) and (6), let us rewrite expression (4) in simplified view:

$$
A=C^{-1} * B
$$

where $C^{-1}-$ correlation failure matrix LSM.

It can also be noticed that $C^{-1}$ is independent of input countings and can be calculated preliminarily and interweaved in the calculating device memory.

For the CHS using the evaluation of modeling dependency between cellular network parameters, KPI, and KQI can be utilized.

\section{Experimental research}

Within the developmental limitations, the service of Internet access based on the $3 \mathrm{G}$ cellular connection technology was checked [30]. The loading of the video file on the mobile device from the Internet has been done (Fig. 7).

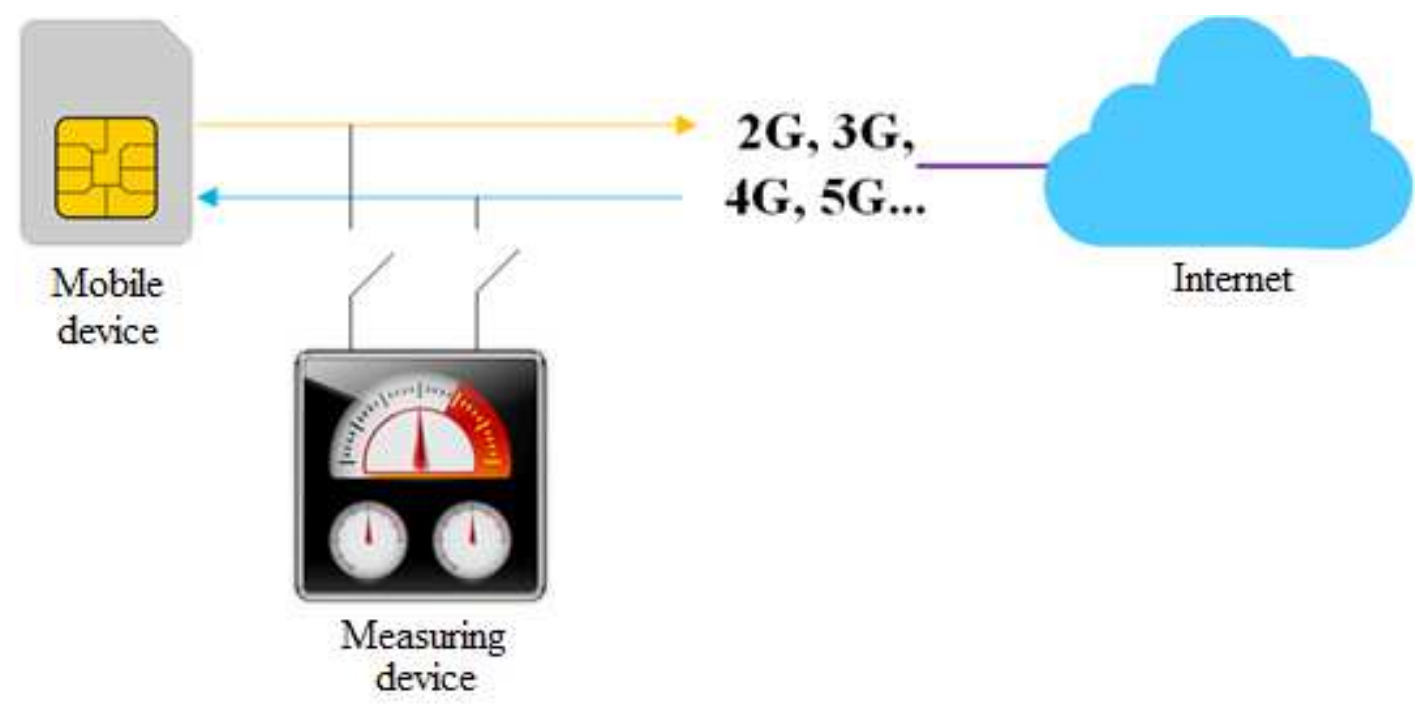

Figure 7. Simplified network architecture 
The KPI parameters were fixed on the measuring device: input stream speed Y1, outgoing stream speed $\mathrm{Y}$ 2, delay $\mathrm{Y} 3$, the power of signal $\mathrm{Y} 4$. On the side of user-KQI parameter-video file loading time Y5.

The experiment consisted of 100 tests. Data was received at unchangeable external conditions for experimental clarity support.

As indicated, the main task is establishing a functional relationship between the parameters of the network KPI and KQI. First of all, it is necessary to approximate the parameters using CHS.

We present the values of the measured parameters in matrix form. For compactness of material 1 and 100 values are resulted:

1) input stream speed, $\mathrm{Mb} / \mathrm{s}$ :

$Y 1=[1.5649452272 ;$

0.5580357144];

2) outgoing stream speed, $\mathrm{Mb} / \mathrm{s}$ :

$\mathrm{Y} 2=[0.9987815608 ;$

0.421874176];

3) delay, ms:

$\mathrm{Y} 3=[165$

184];

4) power of the signal, $\mathrm{dBm}$ :

$\mathrm{Y} 4=[-67 ;$ 
$-55]$

5) video file loading time, $s$ :

Y5 $=[0.1180952384$

\section{$2.5355704696]$}

Let us calculate planning matrix:

$\mathrm{N}=50$

$\mathrm{t}=1: \mathrm{N} ;$ - coordinates of countings of the observing function;

$\mathrm{tu}=1:(\mathrm{N}-1) / 9: \mathrm{N} ;$ - coordinates of spline merging nodes;

[nill,n] = size $(\mathrm{t})$; quantity of observing countings;

$[$ nill,r] $=$ size $(\mathrm{tu}) ;-$ spline merging node quantity;

$\mathrm{p}=$ creat_ps(tu,t,n,r,2);- matrix of planning, parameter 2-cubic spline;

$\mathrm{p}=$

$\begin{array}{lllllll}1.0000 & 0 & 0 & \cdots & 0 & 0 & 0\end{array}$

$\begin{array}{lllllll}0.8026 & 0.2112 & -0.0138 & \cdots & 0 & 0 & 0\end{array}$

$\begin{array}{lllllll}0.5900 & 0.4527 & -0.0427 & \ldots & 0 & 0 & 0\end{array}$

$\begin{array}{lllllll}0 & 0 & 0 & \cdots & -0.0427 & 0.4527 & 0.5900\end{array}$

$\begin{array}{lllllll}0 & 0 & 0 & \cdots & -0.0138 & 0.2112 & 0.8026\end{array}$

$\begin{array}{lllllll}0 & 0 & 0 & \ldots & 0 & 0 & 1.0000\end{array}$

On the basis of received data for each parameter, the spline merging nodes ordinate vector could be calculated and the approximation procedure by using the CHS could be proceeded:

1) input stream speed

$\mathrm{B}=\mathrm{p}^{\prime *} \mathrm{Y} 1$ 
$\mathrm{COB}=\left(\left(\mathrm{p}^{\prime *} \mathrm{p}\right)^{\wedge}(-1)\right)$

$\mathrm{A} 1=\mathrm{COB} * \mathrm{~B}$; - ordinates of the spline merging nodes

$\mathrm{SP} 1=\mathrm{p} * \mathrm{~A} 1 ; \%$ SPLINE

2) outgoing stream speed

$\mathrm{B}=\mathrm{p}^{\prime} * \mathrm{Y} 2$

$\mathrm{COB}=\left(\left(\mathrm{p}^{\prime *} \mathrm{p}\right)^{\wedge}(-1)\right)$

$\mathrm{A} 2=\mathrm{COB} * \mathrm{~B}$

$\mathrm{SP} 2=\mathrm{p}^{*} \mathrm{~A} 2$

3) delay

$\mathrm{B}=\mathrm{p}^{\prime} * \mathrm{Y} 3$

$\mathrm{COB}=\left(\left(\mathrm{p}^{\prime *} \mathrm{p}\right)^{\wedge}(-1)\right)$

$\mathrm{A} 3=\mathrm{COB} * \mathrm{~B}$

$\mathrm{SP} 3=\mathrm{p}^{*} \mathrm{~A} 3$

4) power of the signal

$\mathrm{B}=\mathrm{p}^{\prime *} \mathrm{Y} 4$

$\mathrm{COB}=\left(\left(\mathrm{p}^{\prime *} \mathrm{p}\right)^{\wedge}(-1)\right)$

$\mathrm{A} 4=\mathrm{COB} * \mathrm{~B}$

$\mathrm{SP} 4=\mathrm{p}^{*} \mathrm{~A} 4$

5) video file downloading time

$\mathrm{B}=\mathrm{p}^{\prime} * Y 5$

$\mathrm{COB}=\left(\left(\mathrm{p}^{\prime *} \mathrm{p}\right)^{\wedge}(-1)\right)$

$\mathrm{A} 5=\mathrm{COB} * \mathrm{~B}$

SP5 = p*A5; 
In Fig. 8 (a), the result of input stream speed data approximation process by the cubic hermit spline with marking of the spline merging nodes is depicted. The graph in Fig. 8(b) shows the results of outgoing stream speed data approximation by the CHS with merging node marking. In Fig. 8 (c), approximation result of the experimental test delay data can be seen. In Fig. 8 (d) the result of signal power data approximation is shown. Correlating the data of delay and signal power, it can be seen that they are intercorrelating. As can be seen on Fig. 8 (e), the approximation result of KQI parameter by the CHS with marked spline merging nodes.

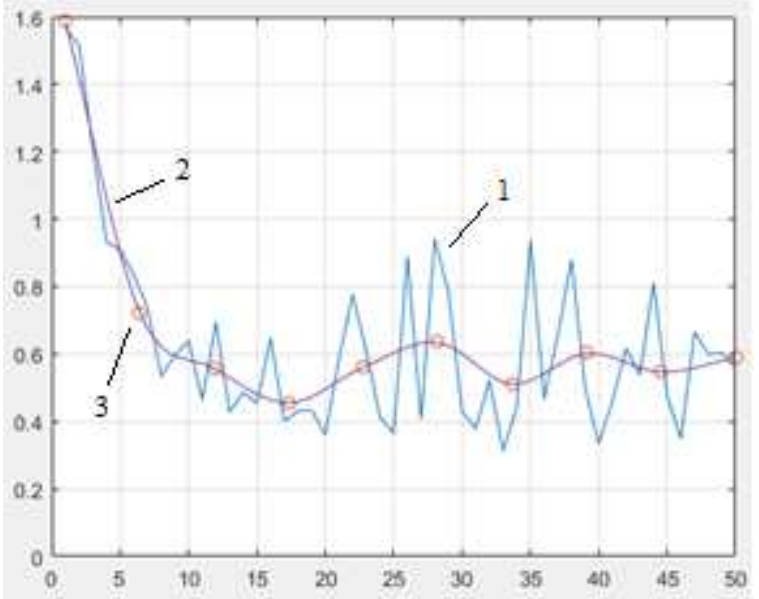

(a)

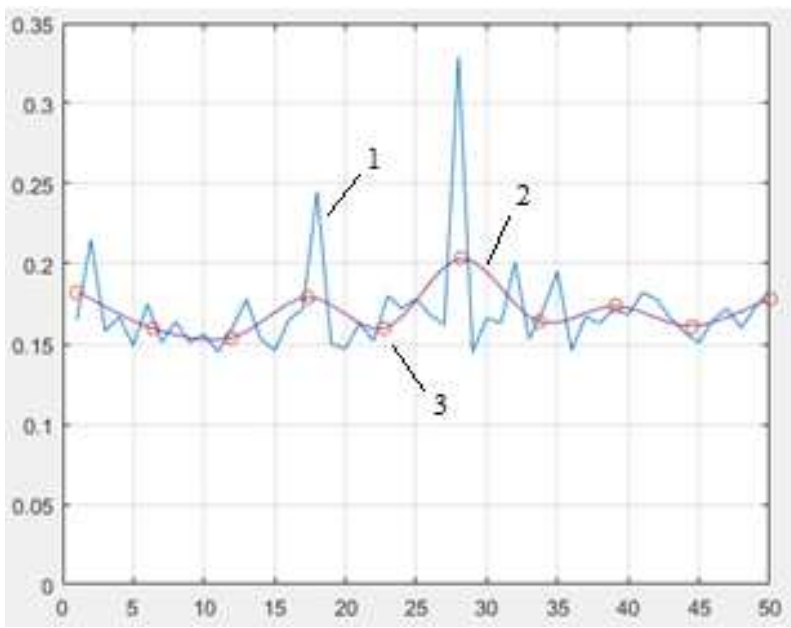

(c)

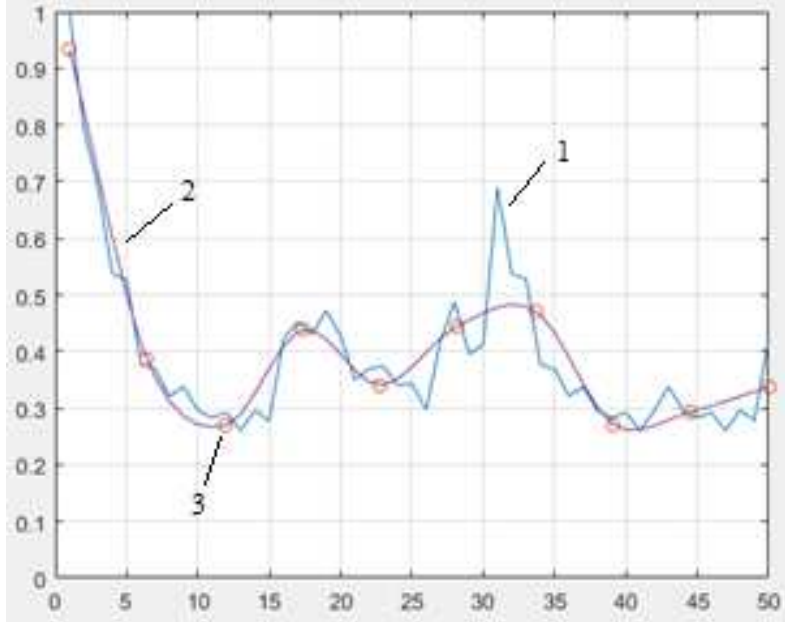

(b)

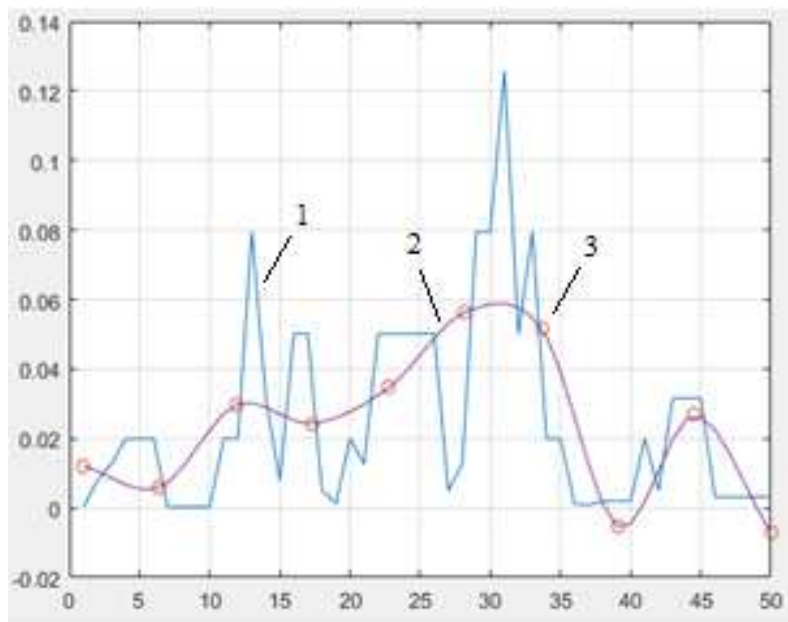

(d) 


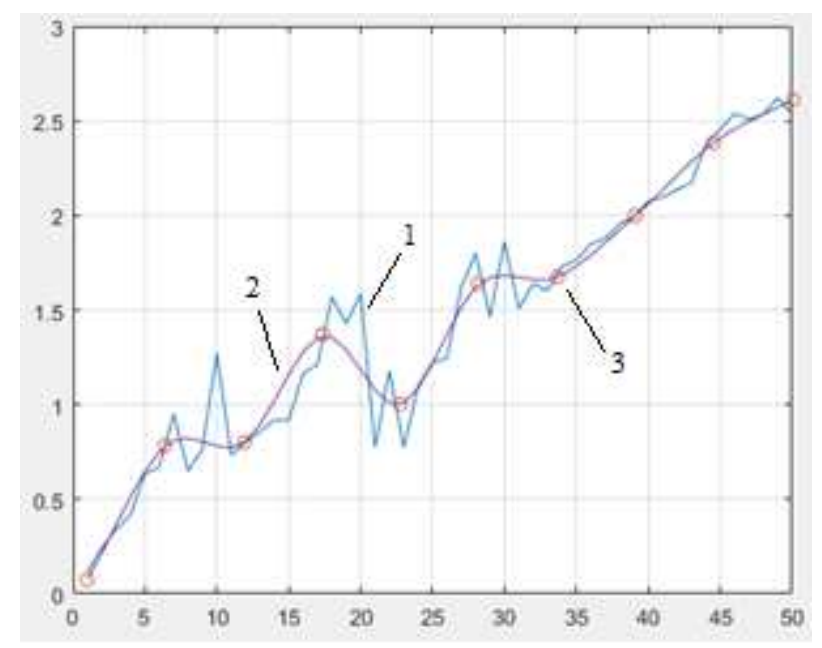

(e)

Figure 8. Input stream speed approximation: 1-curve of measured values; 2 -curve of approximated values; 3-merging nods

(a-input stream speeds; b-output stream speeds; c-delays; d-powers of signal; e-video file loading time)

The next step is the definition of the influence degree of the KPI parameters on KQI:

$\mathrm{PP}=[\mathrm{SP} 1, \mathrm{SP} 2, \mathrm{SP} 3, \mathrm{SP} 4] ;$ - matrix of KPI approximated parameters

$\mathrm{AA}=\left(\left(\mathrm{PP}^{\prime} * \mathrm{PP}\right)^{\wedge}(-1)\right)^{*} \mathrm{PP}^{\prime} * \mathrm{SP} 5 ;$ - coefficients of KPI parameters analytical connection to KQI

$\mathrm{AA}=$

$-1.6011$

$-0.9741$

18.3845

$-11.4475$

Analytical connection coefficients can be found under the condition that root-meansquare forecast failure of the KQI parameter from the KPI parameters would be minimal. 
On the basis of received data, a conclusion can be drawn that the greatest influences on the video loading time are the delay value and value of signal power.

On the basis of the abovementioned data, the statistical equalization of the KQI parameter time rows can be completed, or, in other words, the equalization of KQI process physics on the basis of already determined approximated KPI parameters (Fig. 9).

$$
\begin{gathered}
\Phi=(P P * A A-S P 5)^{2}=\min \\
K Q I=K P I(1) * A A(1)+K P I(2) * A A(2)+K P I(3) * A A(3)+K P I(4) * A A(4) \\
\mathrm{SP} 5 \mathrm{E}=\mathrm{SP} 1 * \mathrm{AA}(1)+\mathrm{SP} 2 * \mathrm{AA}(2)+\mathrm{SP} 3 * \mathrm{AA}(3)+\mathrm{SP} 4 * \mathrm{AA}(4) ;
\end{gathered}
$$

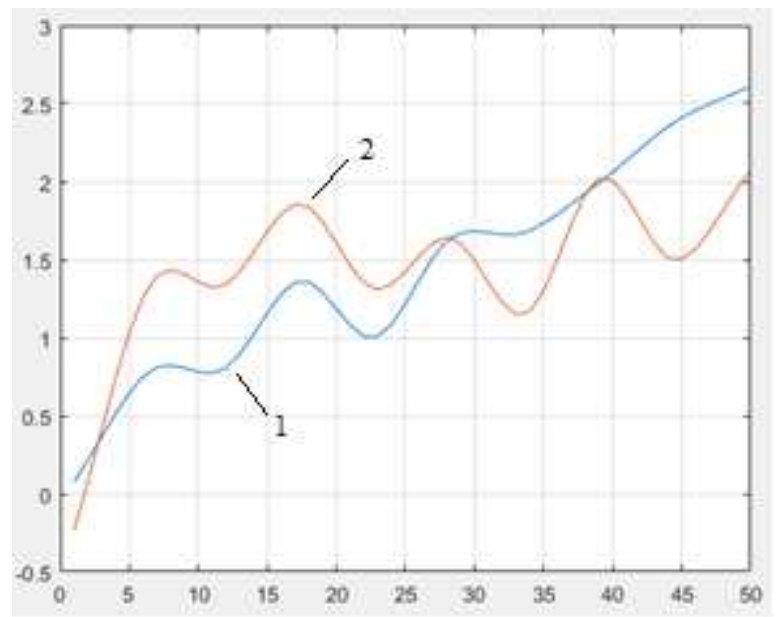

Figure 9. The result of KQI parameter alignment: 1-curve of approximated values; 2-curve of aligned values

The use of splines allows the ability to not only find statistical estimations of the spline-approximation required parameters, but also their confidence intervals, which increases the accuracy and probability of further calculations, which is a definite advantage of the chosen approach.

In our case, it allows use to receive the KQI forecast from the KPI changing. At the perspective of discovery, under such conditions, the next step would be the realization of concrete parameter KPI selection for the modernization and increased user service providing quality level. 


\section{Conclusions}

The cellular network key effectiveness indicators (KPI) and quality indicators (KQI) have been considered in current development and the hierarchy of their interaction that defines product quality for the satisfaction of some adequate level designed by the cellular provider have been defined. It is mentioned that during the selection of some indicators, needed for an adequate service quality evaluation, it is necessary to minimize their quantity and take into account possible "cross-point" influencers of the separate KPI on several different KQI. The parameters and quality indicator summation are needed to reflect all basic interaction quality criteria of cellular instruments with telecommunication network and of user with telecommunication service as product, that is designed by cellular provider respectively to ETSI TS 102 250-1.

In the development, for the aim of the interdependence between QoE and QoS parameters definition, polynomial splines with basic matrix disengaged structure were used. They provide high speedwork during spline calculation, and, in return is very important for real time work during large data array processing.

In addition, a universal form of spline construction is presented for applications in telecommunications, primarily for efficient operation during programming. Namely, a clear software implementation of splines in the MATLAB programming environment is presented.

Therewith, modeling by the developed spline constructing form has been accomplished. In this result, it allows for the determination of the analytical function of the polynomial spline and proves effective filtration features and spline smoothing. Calculated results of root-mean-square departure of polynomial spline from useful signal ans $=0.0082$ is approximately 30 times less than root-mean-square departure of noisy signal from useful ans $=0.2313$, which shows the effective statistical alignment of the noisy signal. 
To achieve the task of improving the quality of services, a method for determining the functional dependency between network parameters, i.e., the impact of key performance indicators on a KQI through the usage of CHS. This method evaluates the degree of influence of each of the KPI parameters on the KQI parameter with a future average data forecast, which leads to the implementation of the choice of a certain KPI parameter for its further improvement or optimization. At the same time, the developed method differs in simplicity of calculations due to what provides high speed calculation that, in turn, is important for work in real time during large data set processing.

\section{Declarations}

\section{Availability of data and materials}

Data sharing not applicable to this article as no datasets were generated or analysed during the current study

\section{Competing Interest}

The authors declare that they have no competing interests.

\section{Funding}

This work was supported in part by the European Commission under the 5G-PPP project 5GTOURS: SmarT mObility, media and e-health for toURists and citizenS (H2020-ICT-20182020 call, grant number 856950).

\section{Acknowledgements}

$\mathrm{N} / \mathrm{A}$

\section{Authors Contribution}

AB carried out the molecular genetic studies, participated in the sequence alignment and drafted the manuscript. JY carried out the immunoassays. MT participated in the sequence alignment. ES participated in the design of the study and performed the statistical analysis. FG conceived of the study, and participated in its design and 
coordination and helped to draft the manuscript. All authors read and approved the final manuscript. All contributors who do not meet the criteria for authorship should be listed in an acknowledgements section.

\title{
Authors Information
}

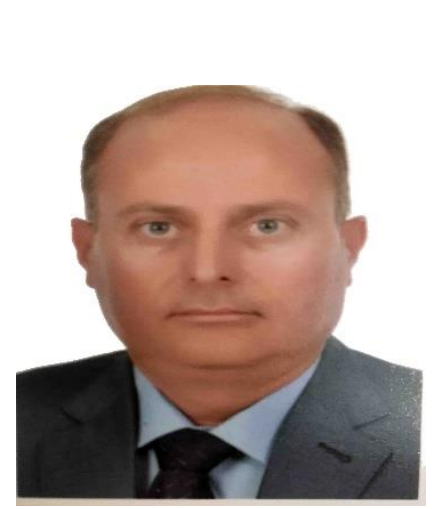

\begin{abstract}
Author Biography
Dr. Jamil S. Al-Azzeh received his PhD Degree in Computer Engineering from great Saint-Petersburg polytechnic university State University - Russia in 2008. Since 2003. Dr. Al-Azzeh has been an associated professor in the Computer Engineering Department. Faculty of Engineering Technology, at Al-Balqa' Applied University. His research interests include computer system architecture, parallel processing, packet switching networks, group communications, fault-tolerance,
\end{abstract} microarchitecture, programmable logic devices, image processing, and microprogramming. $\mathrm{He}$ is the author and a co-author of over 60 papers in international and domestic journals, and more than 20 papers in conference proceedings

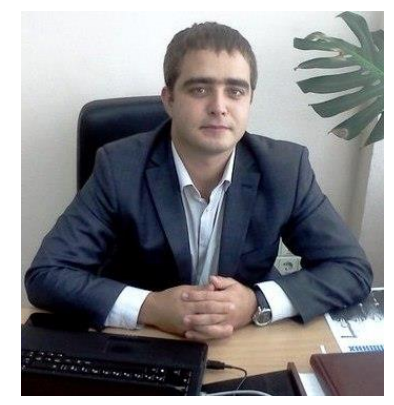

Roman Odarchenko was born in Russia in 1988. He received the B.S. and M.S. degrees in telecommunications from the National aviation university, Kyiv, Ukraine, in 2009 and 2010 and the Ph.D. and DSc. degrees in telecommunications systems and networks from the National aviation university, Kyiv, Ukraine, in 2013 and 2019.

From 2010 to 2017, he was an associated professor in National aviation university. Since 2017, he has been a Researcher in Bundleslab KFT, Budapest, Hungary. He is the author of three books, more than 70 articles, and more than 50 inventions. His research interests include telecommunication systems and networks, mobile networks, wireless systems, software-defined networking, network security systems etc. He is an Associate Editor of the journal Information Security, and holds eleven patents.

Dr. Roman Odarchenko was a recipient of the Cabinet of Ministers of Ukraine scholarship for young scientists in 2015 and 2016.

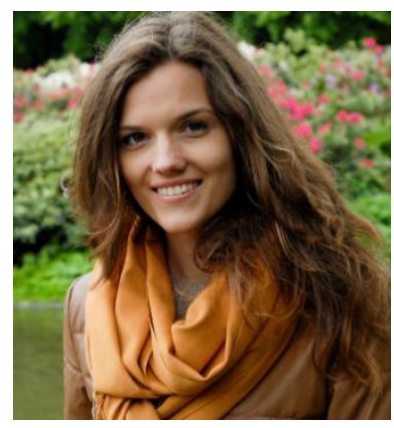

Anastasiia Abakumova was born in Ukraine in 1993. She received the B.S. and M.S. degrees in telecommunications from the National aviation university, Kyiv, Ukraine, in 2015 and 2016. Since 2016 she is a PhD student in Telecommunications and radio technology, Department of Telecommunication systems, National Aviation University. 
From 2013 to 2014, under the EWENT Erasmus Mundus program she studied at the Warsaw Polytechnic (Warsaw, Poland) at the Faculty of Electronics and Information Technology. From 2016 to 2018 she was a teaching assistant in Telecommunication Systems Academic Department of National Aviation University. She is the author of around 30 articles and publications. Her research interests include telecommunication systems and networks, mobile networks, wireless systems, software-defined

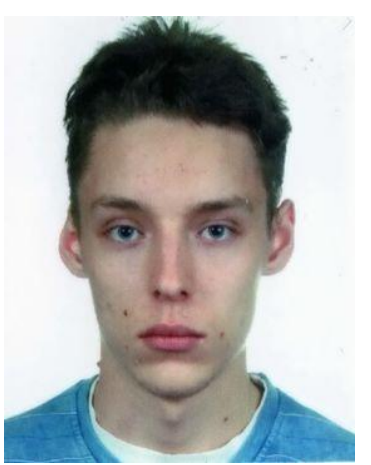
networking, etc.

Serhii Bondar was born in Kyiv, Ukraine in 1994. In 2015 he received B.S. degree in avionics and in 2017 he received MSc degree in aviation management in National Aviation University (Kyiv, Ukraine). From 2017 he is a PhD Student in computer sciences and information technologies. He is currently working at International Research and Training Center for Information Technologies and Systems of the National Academy of Sciences (NAS) of Ukraine and Ministry of Education and Science (MES) of Ukraine. His research interests include unmanned aerial vehicles, intellectual control systems, cybersecurity, data processing etc.

\section{List of Abbreviations}

KPI: Key performance indicator

KQI: Key quality indicator

QoS: Quality of service

CHS: Cubic Hermitian splines

QoE: Quality of Experience

5G: 5-th generation of cellular networks

IP: Internet protocol

MNO: Mobile network operator

ETSI: European Telecommunications Standards Institute

TS: Technical specification

LSM: least squares method

\section{References}


1. Imoize AL, Orolu K, Atayero AA. Analysis of key performance indicators of a 4G LTE network based on experimental data obtained from a densely populated smart city. Data in brief. 2020;29:105304. https://doi.org/10.1016/j.dib.2020.105304

2. Atxutegi E, Fajardo JO, Ibarrola E, Liberal F. Experimental suitability evaluation of standardized QoS measurements over mobile broadband networks. In 2017 International Conference on Performance Evaluation and Modeling in Wired and Wireless Networks (PEMWN) 2017 Nov 28 (pp. 1-6). IEEE. DOI: 10.23919/PEMWN.2017.8308037

3. Wu S, Chen X, Fu J, Chen Z. Efficient VR video representation and Quality assessment. J Vis Commun Image Represent. 2018;57:107-17. DOI: 10.1016/j.jvcir.2018.10.018.

4. QOE4VR: Quality Of Experience For Virtual Reality Applications https://www.fpz.unizg.hr/qoe4vr/index.php/2017/06/26/what-is-quality-of-experienceqoel.

5. Mrvelj Š, Matulin M, Martirosov S. Subjective Evaluation of User Quality of Experience for Omnidirectional Video Streaming. Promet-Traffic\&Transportation. 2020;32(3):40921. DOI: $10.7307 / p t t . v 32 i 3.3444$

6. Xiaoyan L. Moving beyond network traditional KPIs. Huawei Commun. June 2011;60:17.

7. Bellucci P, Cipriani E, Gagliarducci M, Riccucci C. The SMART Project - speed measurement validation in real traffic condition Proceedings. IEEE Intell Transp Syst. 2005;2005. Vienna, 2005, pp. 874-9. doi: 10.1109/ITSC.2005.1520165.

8. Kawai K, Tanabe K, Yamaoka K, Baba KI. Emergency Trunk Reservation Control Using Waiting Queue for Accommodating More General Calls. In2019 International Conference on Computing, Networking and Communications (ICNC) 2019 Feb 18 (pp. 287-291). IEEE. doi: 10.1109/ICCNC.2019.8685500.

9. Latr S, Staelens N, Simoens P. On-line estimation of the QoE of progressive download services in multimedia access networks. Las Vegas: ICOMP; 2008. p. 14-7. 
10. Ghotbabadi AR, Feiz S, Service Dr. RB. Quality measurements: a review. Int J Acad Res Bus Soc Sci. February 2015;5(2).

11. Goldstein AB, Zarubin AA, Onufrienko AV, Elagin VS, Belozertsev IA. Synchronization of delay for OTT services in LTE. In2018Systems of Signal Synchronization, Generating and Processing in Telecommunications (SYNCHROINFO) 2018 Jul 4 (pp. 1-4). IEEE.

12. Mok RK, Chan EW, Luo X, Chang RK. Inferring the QoE of HTTP video streaming from user-viewing activities. InProceedings of the first ACM SIGCOMM workshop on Measurements up the stack 2011 Aug 19 (pp. 31-36).13. Mohamed S, Rubino G. A study of real-time packet video Quality using random neural networks. On Circuits Syst Video Tech IEEE, Trans. 2002;12(12):1071-83.

14. Liotou E, Tsolkas D, Passas N. A roadmap on QoE metrics and models. In2016 23rd International Conference on Telecommunications (ICT) 2016 May 16 (pp. 1-5). IEEE. doi: 10.1109/ICT.2016.7500363.

15. Amour L, Tong V, Souihi S, Tran HA, Mellouk A. Quality Estimation Framework for Encrypted Traffic (Q2ET). In2019 IEEE Global Communications Conference (GLOBECOM) 2019 Dec 9 (pp. 1-6). IEEE.

Doi:10.1109/GLOBECOM38437.2019.9014234.

16. Aggarwal V, Halepovic E, Pang J, Venkataraman S, Yan H. Prometheus: Toward qualityof-experience estimation for mobile apps from passive network measurements. InProceedings of the 15th Workshop on Mobile Computing Systems and Applications 2014 Feb 26 (pp. 1-6).

17. Balachandran A, Sekar V, Akella A, Seshan S, Stoica I, Zhang H. A quest for an internet video quality-of-experience metric. InProceedings of the 11th ACM workshop on hot topics in networks 2012 Oct 29 (pp. 97-102). 
18. Claeys M, Latre S, Famaey J, De Turck F. Design and evaluation of a self-learning. IEEE Commun Lett. April 2014;18(4). No:716-9. doi:

10.1109/LCOMM.2014.020414.132649.

19. LaTorre A, Pena JM, Muelas S, Pascual C. Quality measures to adapt the participation in MOS. Vol. 2009. Trondheim: IEEE Publications Congress on Evolutionary Computation; 2009. p. 888-95. doi: 10.1109/CEC.2009.4983039.

20. Jonathan Liebenau, Silvia Elaluf-Calderwood, Patrik Karrberg. Strategic challenges for the European Telecom Sector: the consequences of imbalances in Internet traffic. J Inf Policy. 2012;2:248-72. doi: 10.5325/jinfopoli.2.2012.0248.

21. Arzhanrsev SV. Key mobile network performance indicators choise for customer experience estimation. T-Comm. 2016;10(6):69-72., "Vocabulary for performance and quality of service 2006., "The Open Group,” October 2004.

22. Malachivsky PS, Skopetsky VV. Continuous and smooth minimax spline approximation/ed. I.V. Sergienko; NAS of Ukraine, Institute of Cybernetics. VM Glushkova, Center Mat. modeling Inst example. probl. mechanics and mathematics. Ya. S. Prydryhacha. - Kyiv: Nauk. opinion, 2013.

23. Brumback BA, Rice J. Smoothing spline models for the analysis of nested and crossed samples of curves. J Am Stat Assoc. 1998;93:V.

24. Ramsay TO. Spline smoothing over difficult regions. J R Stat Soc B. 2002;64(2):V. doi: 10.1111/1467-9868.00339.D. Carry, Durban M. Flexible smoothing with P-splines: a unified approach. Stat Modell. 2002.

25. Carry ID, Durban M. Flexible smoothing with P-splines: a unified approach. Stat Modell. 2002. 
26. Silaev DA, Amilyushchenko AV, Lukyanov AI. Korotaev DO Semi-local smoothing splines of class C1/Proceedings of the seminar named after. Petrovsky Mosc Issue. $2007 ; \mathrm{I}(\mathrm{G}): 26$.

27. Abakumova AO. Polynomial spline for solving applied problems in telecommunications and radio engineering/Abakumova A.O., Slipukhina O.O., Odarchenko R.S., Yanovsky F.Y., Shutko V.M.. Series: Technical Sciences.” -. 2018;29(68) № 5:60-4.

28. Shelevitskiy IV. Interpolation splines in digital signal processing problems.//Exponenta Pro. Math Appl. 2003;4. Shelevitsky IV, Shutko MO, Shutko VM, Kolganova OO. Splines in digital data and signal processing; 2007.

29. Rohr K, Fornefett M, Stiehl HS. Spline-based elastic image registration: integration of landmark errors and orientation attributes. Comput Vis Image Underst. 2003;90(2):15368. doi: 10.1016/S1077-3142(03)00048-1.

30. Abakumova AO. Determination of the dependence between the parameters of the cellular network by a cubic Hermitian spline/Abakumova A.O., Odarchenko R.S. Shutko V.M. // Scientific and Technical Journal. Microsyst Electron Acoust. 2018;23(6) (107):34-41.

\section{Figure Title and Legend}

Figure 1. QoE estimation framework

Figure 2. Graphic representation of the service quality control method

Figure 3. Estimation method of QoE based on KPI measurements

Figure 4. Polynomial spline

Figure 5. Schematic planning matrix

Figure 6. Representation of basic functions

Figure 7. Simplified network architecture

Figure 8. Input stream speed approximation: 
1-curve of measured values; 2 -curve of approximated values; 3 -merging nods (a-input stream speeds; b-output stream speeds; c-delays; d-powers of signal; e-video file loading time)

Figure 9. The result of KQI parameter alignment: 1-curve of approximated values; 2-curve of aligned values 


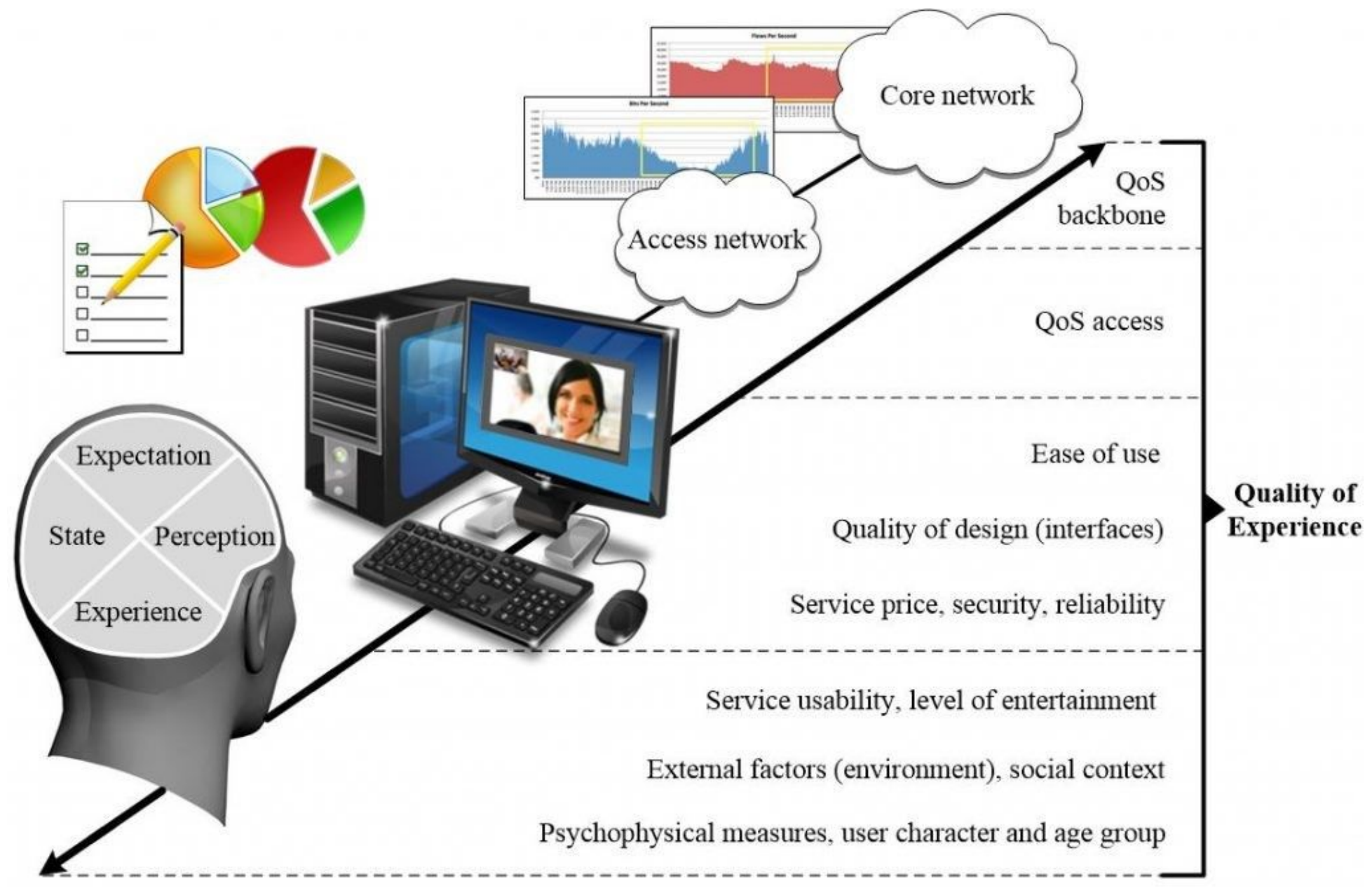

Figure 1

QoE estimation framework

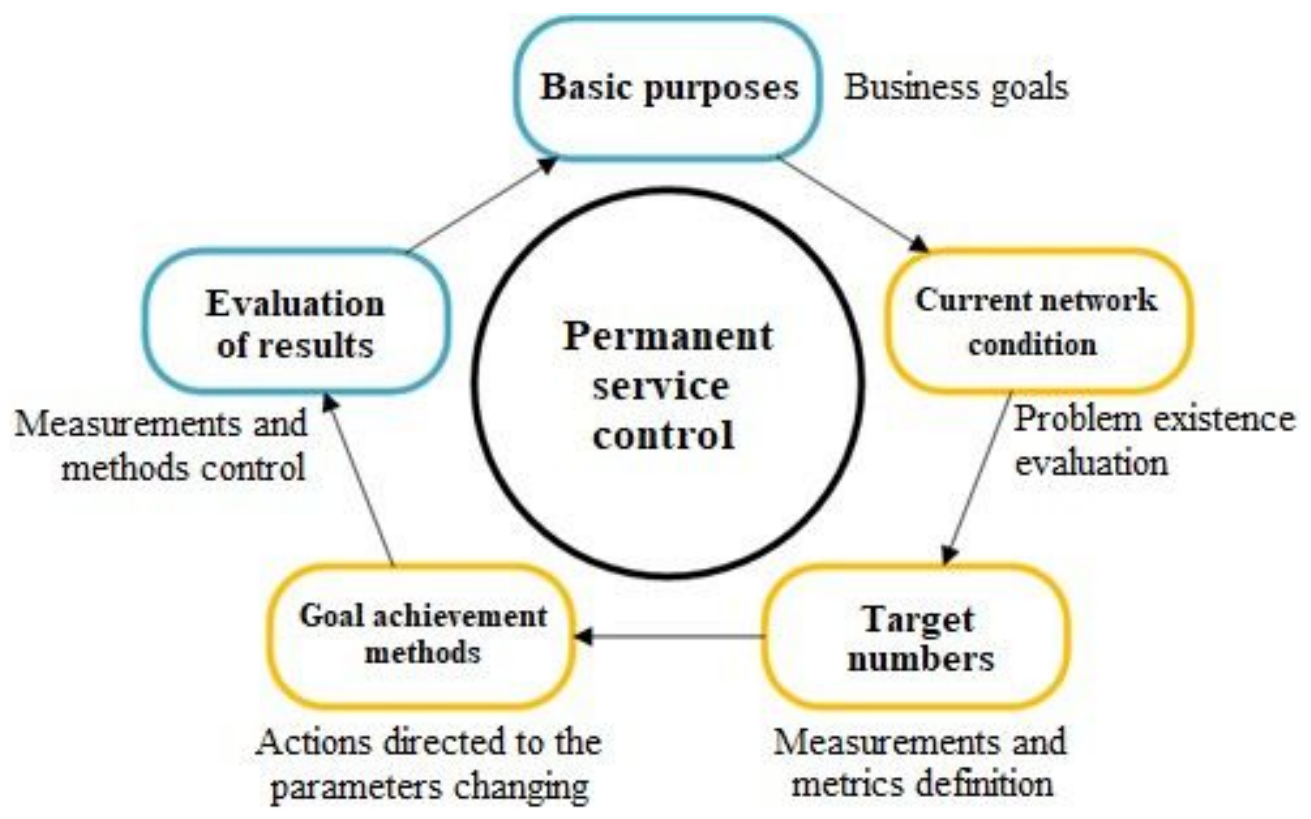


Figure 2

Graphic representation of the service quality control method

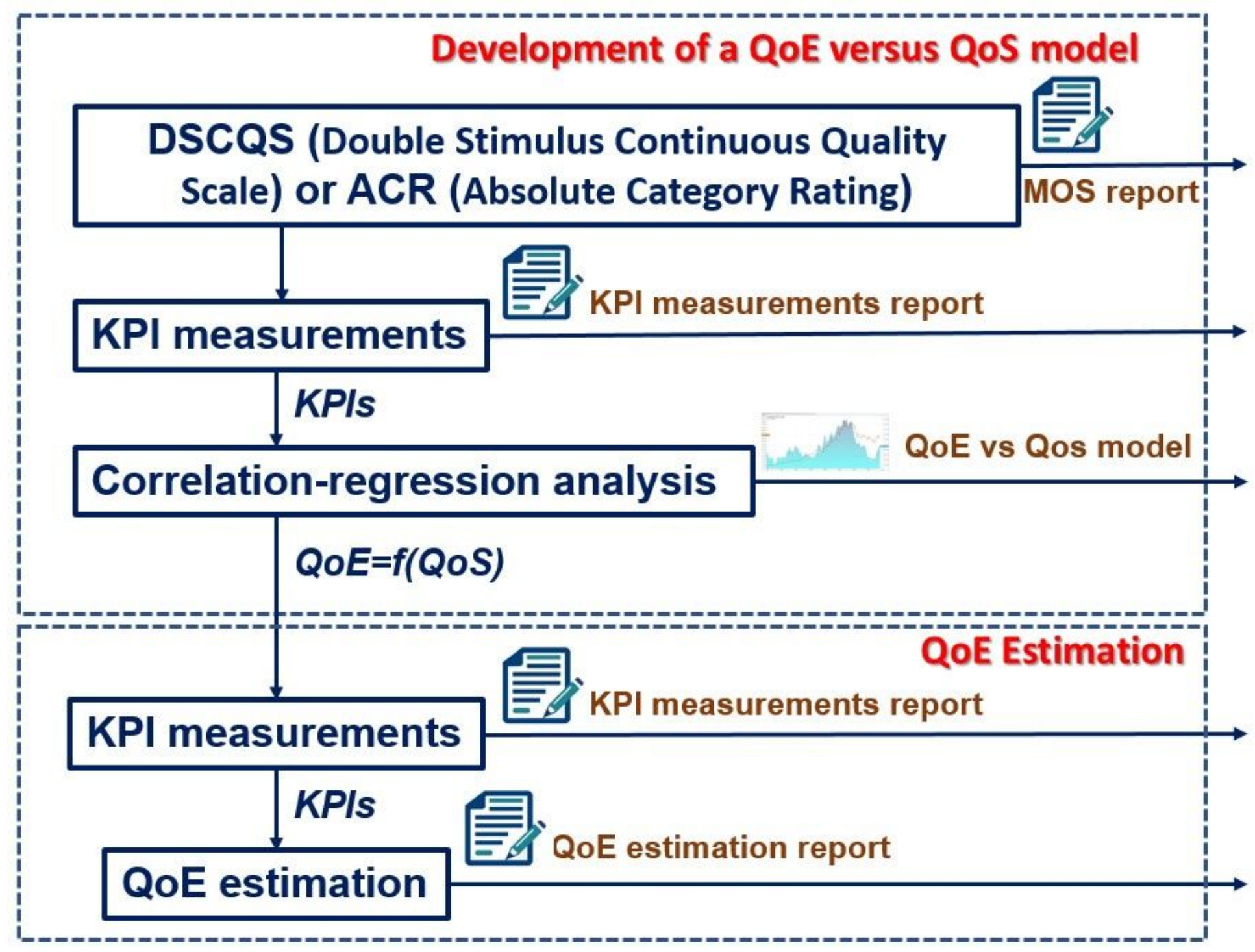

Figure 3

Estimation method of QoE based on KPI measurements

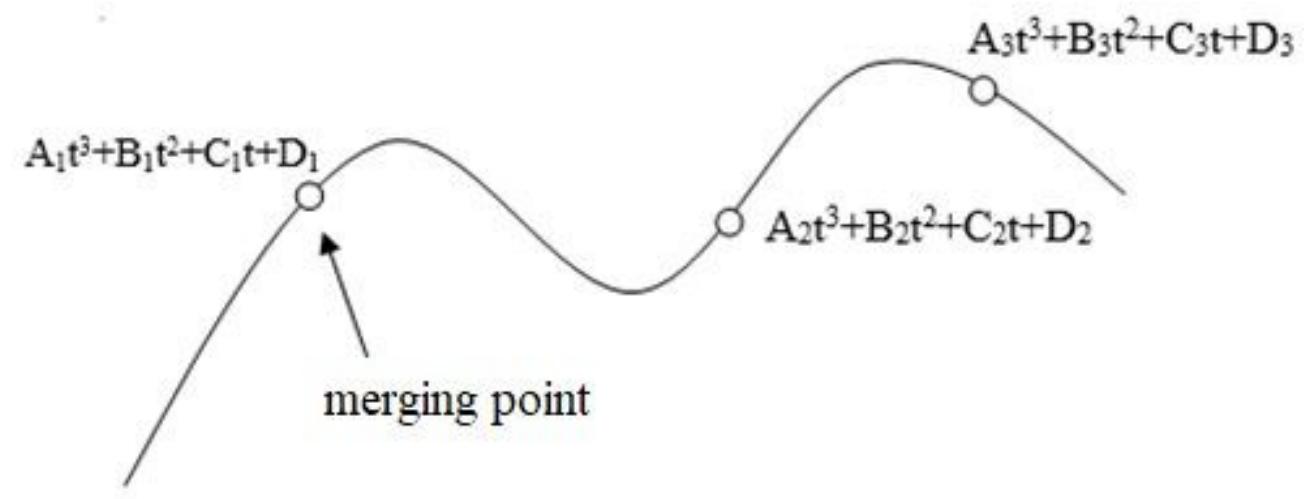

Figure 4 
Polynomial spline

$$
P=\underbrace{\left(\begin{array}{cccc}
\square \square & 0 & \cdots & 0 \\
0 & \square & \cdots & 0 \\
\cdots & \cdots & \cdots & \cdots \\
0 & 0 & \cdots & \square \square
\end{array}\right)}_{R}\}^{N}
$$

\section{Figure 5}

Schematic planning matrix

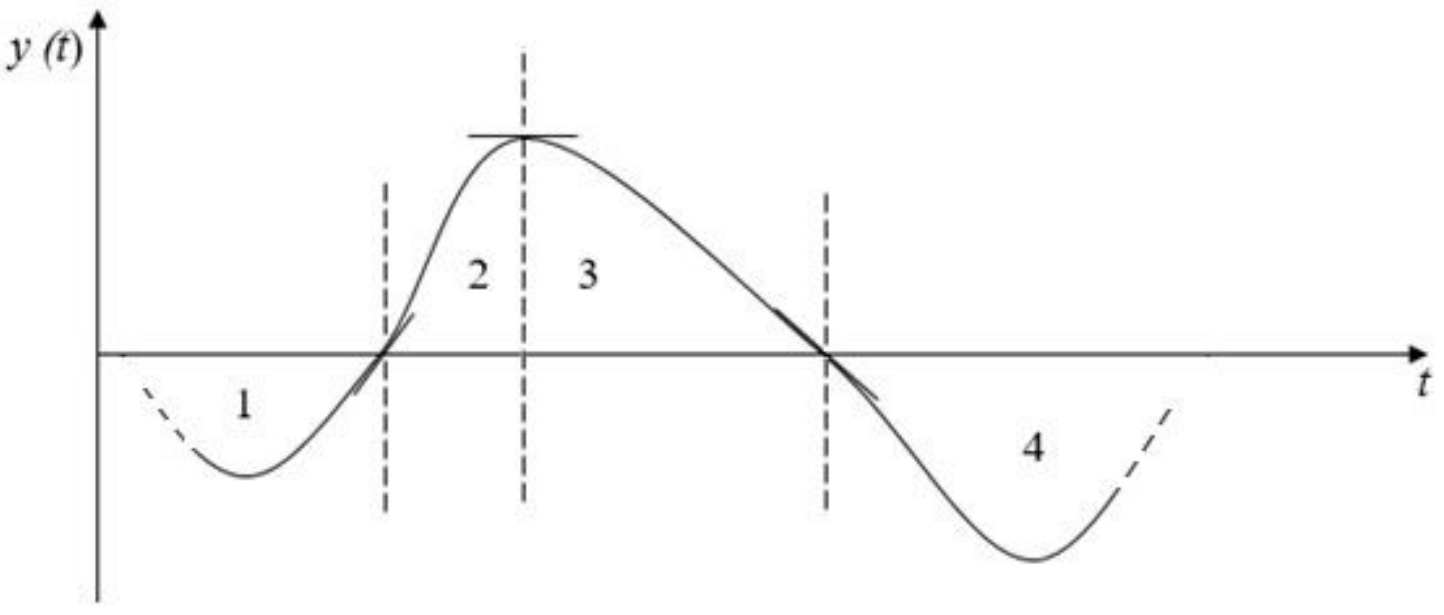

\section{Figure 6}

Representation of basic functions

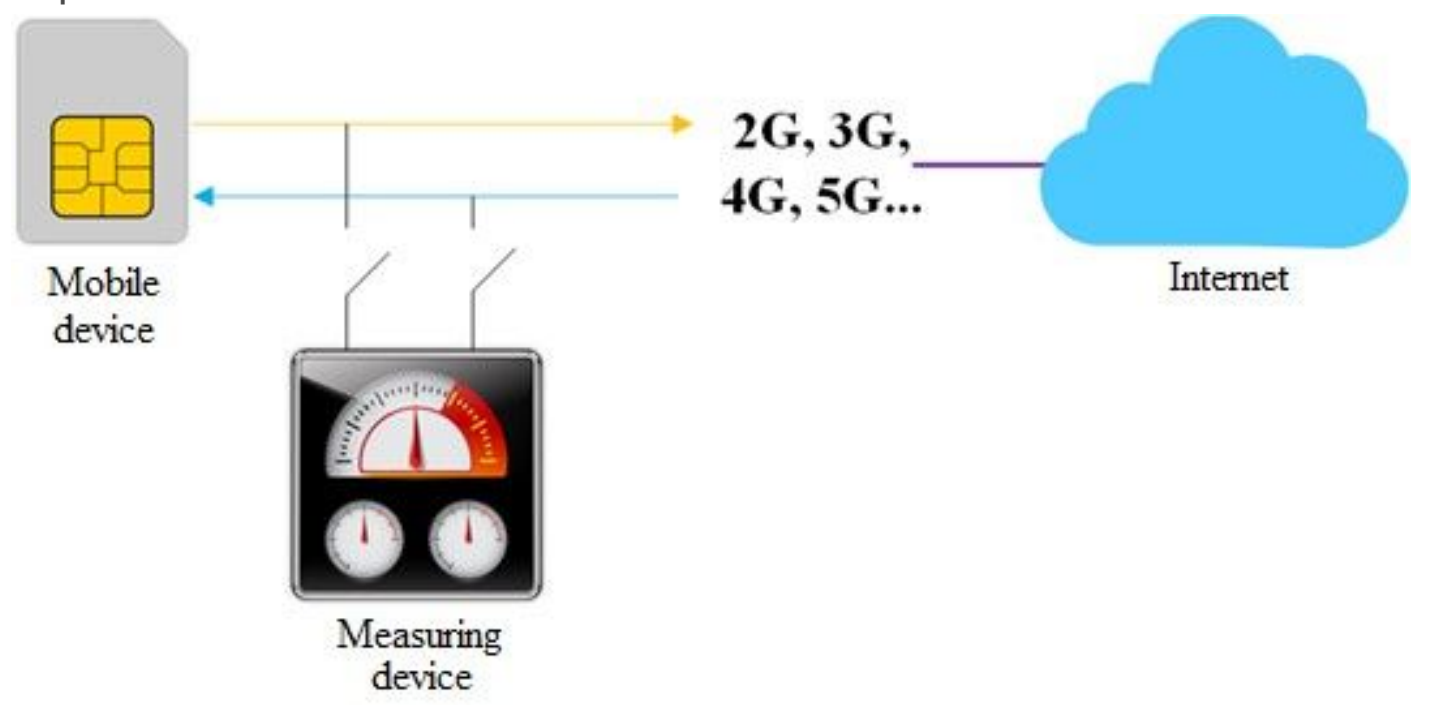

Figure 7

Simplified network architecture 


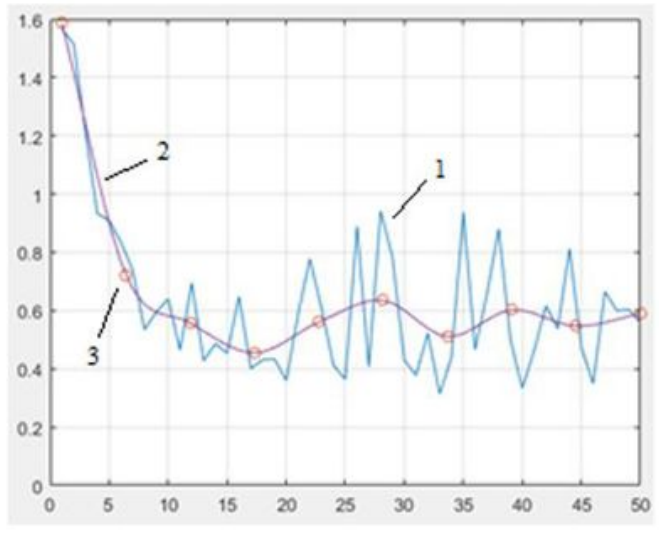

(a)

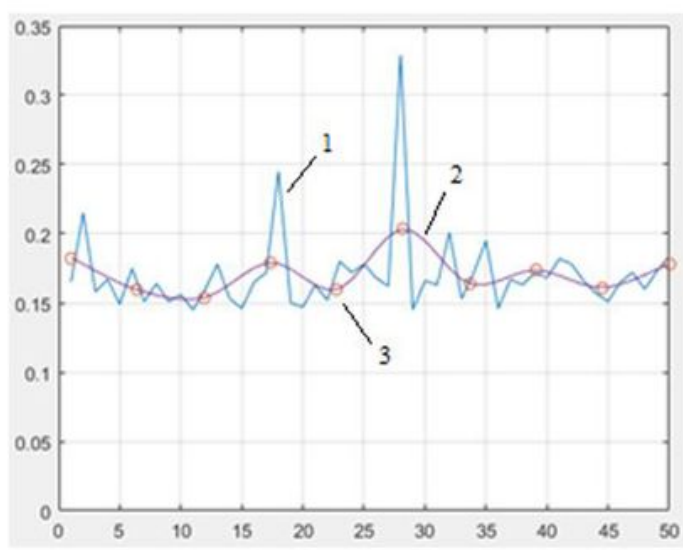

(c)

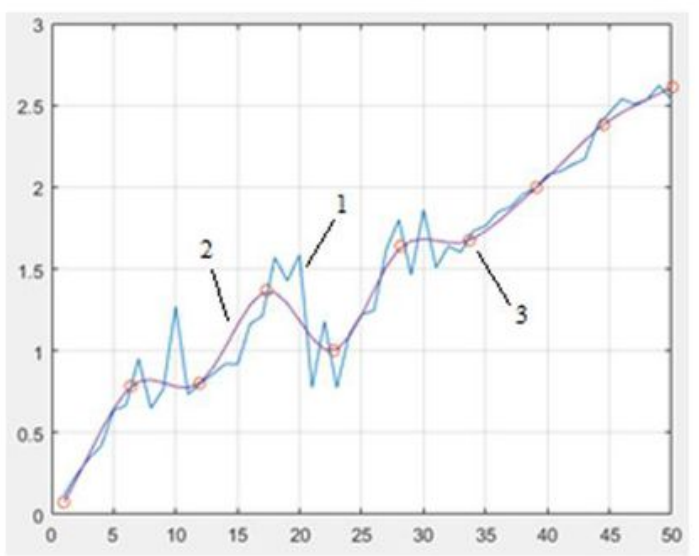

(e)

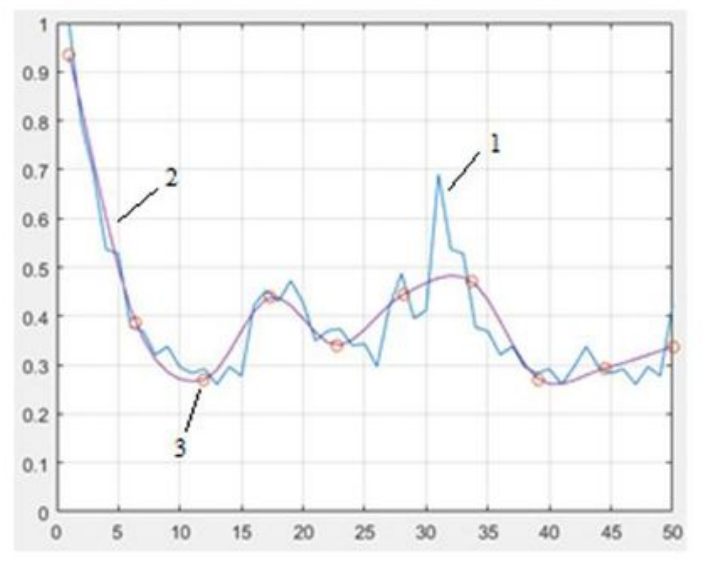

(b)

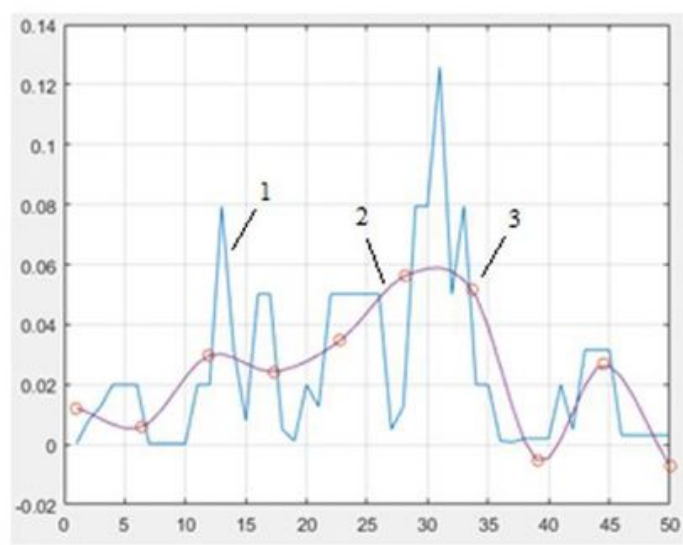

(d)

\section{Figure 8}

Input stream speed approximation: 1-curve of measured values; 2 -curve of approximated values; $3-$ merging nods (a-input stream speeds; b-output stream speeds; $c$-delays; $d$-powers of signal; $e$-video file loading time) 


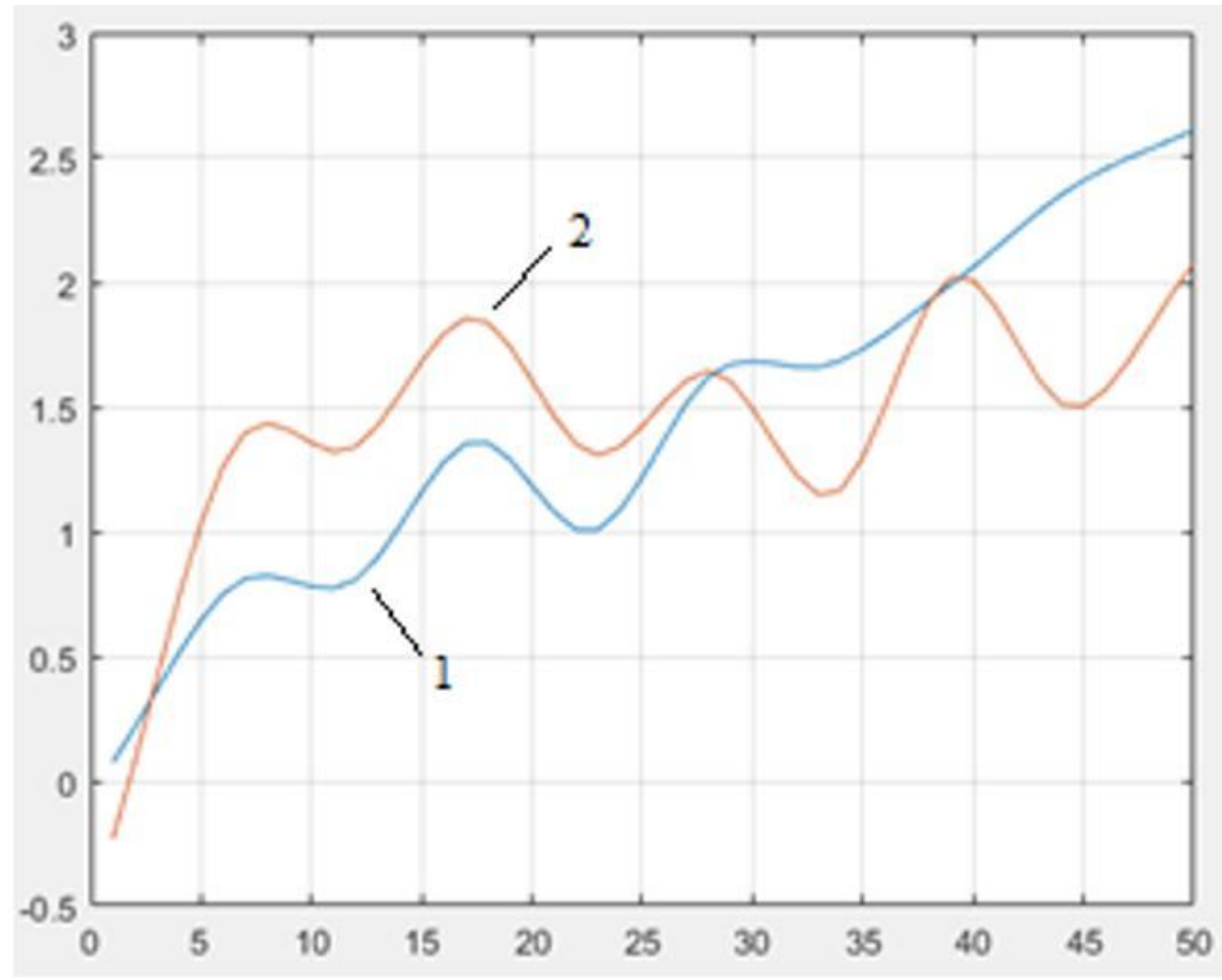

Figure 9

The result of KQI parameter alignment: 1-curve of approximated values; 2 -curve of aligned values 